\title{
Gallstones in elderly patients: Impact of laparoscopic cholecystectomy
}

\author{
A Montori MD FACs, M Boscaini MD, M Gasparrini MD, G Miscusi MD, \\ L Masoni MD, M Onorato MD, J Montori MD
}

\begin{abstract}
A Montori, M Boscaini, M Gasparrini, et al. Gallstones in elderly patients: Impact of laparoscopic cholecystectomy. Can J Gastroenterol 2000;14(11):929-932. The use of laparoscopic cholecystectomy (LC) in elderly patients may pose problems because of their poor general condition, especially of cardiopulmonary function. Moreover, these patients present with acute cholecystitis and associated common bile duct stones more often than their younger counterparts. From 1990 to 1999, the authors performed $943 \mathrm{LCs} ; 31(3.2 \%)$ were attempted on elderly patients, $11(35 \%)$ of which were on an emergency basis because of acute cholecystitis, cholangitis or acute biliary pancreatitis. Ten per cent of LCs needed to be converted to an open cholecystectomy, most often because of an increase in the partial pressure of carbon dioxide in the blood produced by excessive operative time. A gasless procedure was used in the last three years of the study on eight cases; the overall rate of conversion from LC to open cholecystectomy in this group was $0 \%$. Associated gallbladder and common bile duct stones were found in five (16\%) patients (four preoperative LC endoscopic sphincterotomy and one transcystic approach). The success rate in both of these cases was $100 \%$, overall morbidity was $29 \%$ and there was no mortality. These results show that LC is a feasible and safe procedure for use in elderly patients. Gasless LC should be preferred in patients classified as American Society of Anesthesiologists' class III because an excessive duration of operation is the most common reason for converting to an open cholecystectomy.
\end{abstract}

Key Words: Elderly patients; Gallstones; Laparoscopic cholecystectomy

\section{La lithiase vésiculaire chez les sujets âgés :} Impact de la cholécystectomie laparoscopique

RÉSUMÉ : La cholécystectomie laparoscopique (CL) chez les sujets âgés peut poser des problèmes pour les mauvaises conditions générales et en particulier les fonctions cardiorespiratoires. Néanmoins, ces patients sont atteints par des cholécystites aiguës associée à lithiase de la VBP plus souvent des sujets jeunes. De 1990 à 1999 les auteurs on réalisées 943 CL: $31(3,2 \%)$ concernant des patients âgés, dont 11 (35\%) avait étés hospitaliser en urgence à cause de cholécystite aiguë, cholangite ou de pancréatite biliaire aiguë. Dix pour cent des CL on nécessitées une conversion en cholécystectomie ouverte, le plus souvent à cause d'une élévation du niveau hématique de la pression partiel de $\mathrm{CO}_{2}$ en rapport avec des longs temps opératoire. Dans les trois dernières années de cette étude, des interventions avec la technique "gasless" ont étè réaliser en huit cas: le taux total de conversion de CL à cholécystectomie ouverte a ètè en ce groupe de $0 \%$. Une lithiase de la voie biliaire principale associée à la lithiase vésiculaire a été retrouvée en cinq (16\%) patients (quatre sphinctérotomies endoscopiques pré-CL et un abord trans cystique). Le taux de succès a èté dans ces derniers cas de 100\% la morbidité de $29 \%$ et pas de mortalité. Ces résultats montrent que la CL est une procédure sure et faisable pour son utilisation chez les sujets âgés. La CL "gasless" doit être préfère pour les patients classifies en classe ASA III parce que les long temps opératoires sont la raisons plus fréquente de conversion à la cholécystectomie ouvert.
$\mathrm{L}$ aparoscopic cholecystectomy (LC) accounts for $80 \%$ to $83 \%$ of the cholecystectomies performed, and since its introduction in 1987, its use has been accompanied by a major increase in the rate of cholecystectomies (1).
LC is the procedure of choice in the treatment of symptomatic gallstones. Diseases of the biliary tract are the most common conditions requiring intra-abdominal surgery in elderly patients (older than 70 years). Growth of the geriat- 


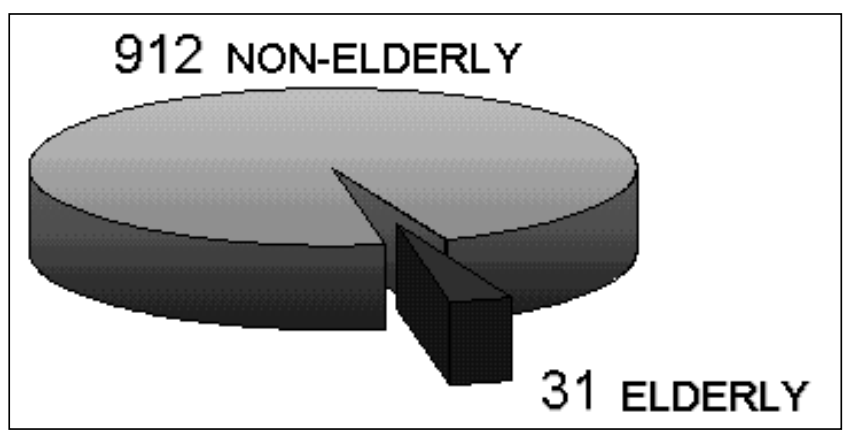

Figure 1) The authors' experience with laparoscopic cholecystectomy in 943 patients from 1990 to 1998

ric population is resulting in increased biliary pathology, which is, therefore, becoming more frequent in the medical environment (2).

Moreover, complications and adverse outcomes of gallstones are more frequent in elderly people. Obviously, an emergency biliary procedure carries higher risks than an elective operation. Elderly patients with gallstones appear to be excellent candidates for $\mathrm{LC}$ when the disease is uncomplicated. In fact, in elderly patients with chronic, uncomplicated gallstone disease (no previous recurrent cholecystitis, associated gallbladder and common bile duct stones, or biliary pancreatitis), the rate of conversion to an open cholecystectomy is similar to that in younger patients undergoing $\mathrm{LC}$ ( $7 \%$ and $5 \%$, respectively). On the other hand, elderly patients are more likely than young patients to present with acute complications of gallstone disease such as acute cholecystitis, gallstone pancreatitis and common bile duct stones; in these circumstances, the conversion rate is higher in elderly patients with complicated gallstones than in young patients $(2,3)$. The aim of the present study is to evaluate the feasibility of laparoscopic surgery and other new techniques in elderly patients, even in emergency situations.

\section{PATIENTS AND METHODS}

From 1990 to 1999, the authors performed 943 LCs. Thirtyone $(3.2 \%)$ procedures were attempted on elderly patients; $11(35 \%)$ of these were treated in an emergency because of acute complications such as acute cholecystitis, cholangitis or acute biliary pancreatitis (Figures 1,2). In the same time period, 12 (37\%) other elderly patients were treated urgently by open surgery because of unfavourable preoperative selection criteria.

The rate of conversion from LC to open cholecystectomy was $10 \%$ in elective surgery and $9 \%$ in emergency surgery, most often because of an increase in the partial pressure of carbon dioxide in the blood as a result of excessive operative time. Because of these results, the last eight consecutive elderly patients were treated with the use of the gasless technique; the conversion rate in this group was $0 \%$. Five patients $(16 \%)$ were found to have associated common bile duct $(\mathrm{CBD})$ stones and were treated with different approaches - preoperative endoscopic sphincterotomy (ES) in four patients and transcystic laparoscopic CBD clearance in

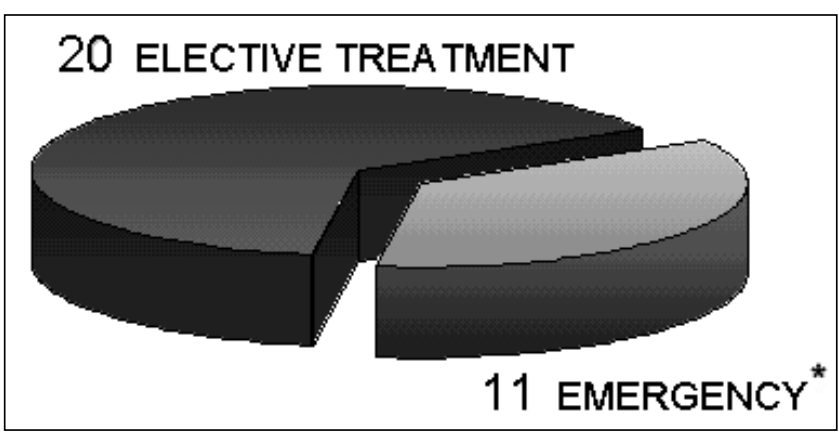

Figure 2) Prevalence of laparoscopic cholecystectomy in 31 elderly patients from 1990 to 1998. *Acute cholecystitis, cholangitis, biliary pancreatitis

one patient. The success rate was $100 \%$, overall morbidity was $29 \%$, and there was no mortality.

\section{DISCUSSION}

Pathogenesis: The pathogenesis of gallstones is complex and multifactorial; gallstones are no longer considered to be a unique entity but a heterogeneous disease that includes at least three different subgroups - cholesterol stones, pigment stones, which can be distinguished on the basis of their colour (black or brown) and mixed stones. While cholesterol stones are formed by cholesterol supersaturation of the bile in the gallbladder and crystal aggregation (nucleation), the most important etiopathogenetic factors in the formation of pigment stones are the precipitation of unconjugated bilirubin excreted in excess (black stones) and the precipitation of calcium-palmitate as a result of inflammatory processes (brown stones).

Symptomatology: The clinical symptoms of gallstones are characterized by right upper or epigastric pain, generally after meals; nausea and vomiting may occur during the attack. The pain may persist for several hours; generally, no fever or other signs of inflammation are present. Patients with gallstones may complain of intolerance to fatty foods. Chronic inflammatory changes are found in the gallbladder of many symptomatic patients with gallstones, but gallstones may also be present in a normal gallbladder, and symptoms may also occur in the absence of inflammation.

Generally, $22 \%$ of patients with gallstones are symptomatic and $78 \%$ are asymptomatic; the prevalence of stones or symptoms increases with age, and is higher in women than in men ( $19 \%$ and $9 \%$, respectively), with an overall prevalence of $14 \%$. Obesity (body mass index higher than 28 ), age (older than 40 years), familiarity (hereditary factors), number of pregnancies and hypertriglyceridemia are other associated factors. The incidence of gallstones is approximately $0.5 \% /$ year. Associated diseases such as diabetes, hepatic cirrhosis, angina, myocardial infarction and peptic ulcer are more frequently associated with gallstones in elderly patients $(4,5)$.

Clinical options and laparoscopic treatment: The initial therapy of biliary colic, after diagnosis, is parenteral administration of an antispastic drug to relieve the pain - a procedure that may help to relax the gallbladder as well. The 


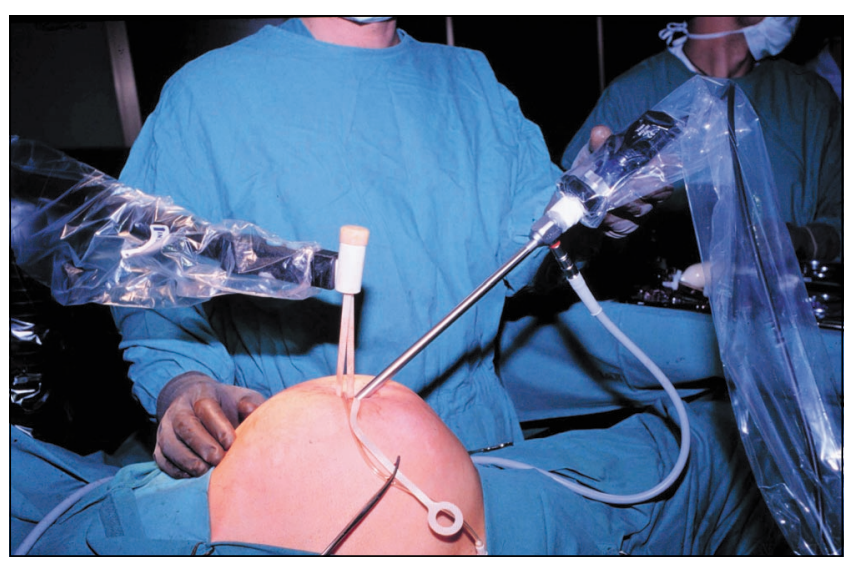

Figure 3) Gasless laparoscopy using a Laparolift system (Origin Medsystems Inc, USA)

definitive treatment of patients with symptomatic gallstones is cholecystectomy, in particular LC. It is well known that carbon dioxide in the pneumoperitoneum increases the intra-abdominal pressure, with the reduction of splanchnic perfusion, respiratory activity, renal perfusion and urine output. If all of these factors are considered, elderly and nonelderly patients with chronic, uncomplicated gallstone disease who undergo LC have similar conversion rates ( $7 \%$ and $5 \%$, respectively). The short duration of the surgical time plays an important role, and the gasless method should be preferred over the traditional method (6-8).

Gasless laparoscopy (isobaric management) is an alternative surgical procedure that has the advantages of laparoscopy and open surgery. Gasless laparoscopy eliminates all the complications related to pneumoperitoneum and the risk of a blind abdominal puncture with the Veress needle or with the first trocar (9-11). The advantages are particularly evident in patients with high cardiopulmonary risks and in those with complicated gallstones, especially elderly patients. In these subjects, a better hemodynamic response, a lower risk of respiratory acidosis and protection against renal ischemia can be obtained. Moreover, nausea, vomiting and pain are less frequent with gasless laparoscopy than with the use of a carbon dioxide pneumoperitoneum (12). These results can be achieved by the use of two different devices - the Laparolift (Origin Medsystems Inc, USA) (Figure 3) and the LaparoTenser systems (Lucini Surgical Concepts, Italy) (Figure 4). While the Laparolift is inserted in the abdominal wall, the LaparoTenser creates a ceiling by inserting two subcutaneous steel wires to act as beams of a tent just above the organ to be operated. With this technique, a low pressure pneumoperitoneum (maximum of 4 to $5 \mathrm{mmHg}$ ) can be used to create a wider abdominal camera view. The amount of intra-abdominal space is determined by the area of the raised abdominal wall, and the maximal height can be obtained by 'lifting' the abdominal wall as perpendicularly as possible. The intra-abdominal space created by these gasless techniques is as good, if not better, than that of the traditional method $(10,11)$.

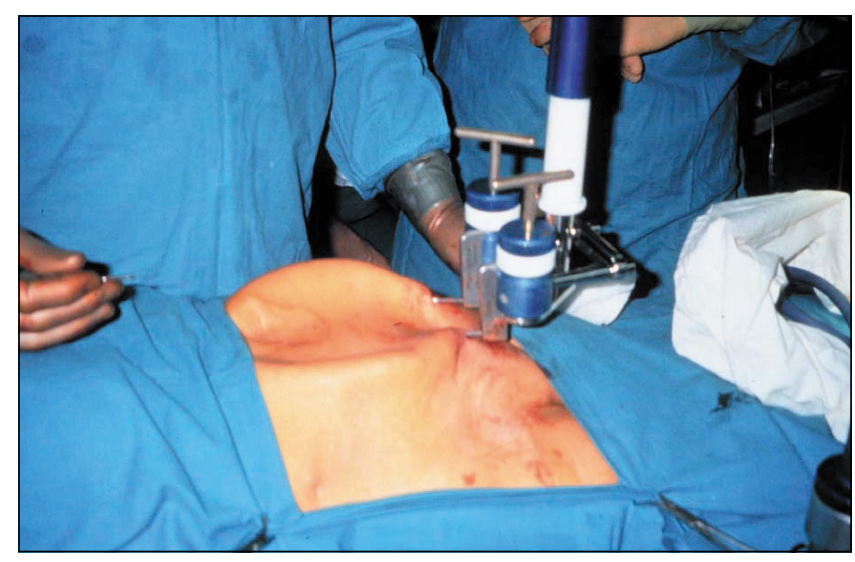

Figure 4) Gasless laparoscopy using a LaparoTenser system (Lucini Surgical Concepts, Italy)

Treatment of associated gallbladder and CBD stones: Gallbladder and CBD stones occur simultaneously in $21 \%$ of elderly patients compared with $5 \%$ of younger patients. When LC came into use, ES was already the preferred method for the management of ductal calculi in patients with or without a gallbladder, on the basis of the reported $90 \%$ success rate in obtaining complete stone clearance with only about $7 \%$ morbidity $(12,13)$. Preference for the sequential approach, with prior ES, may be justified on the basis of different considerations, such as better patient compliance, simplification of the surgical procedure or avoidance of biliary drainage in the case of coledochotomy (14-16).

When CBD stones are identified before surgery, treatment by sequential ES and LC seems to be the logical and least invasive approach. If CBD stones are found during LC, there is a dilemma regarding whether to convert immediately to open CBD exploration or to postoperative ES (17). Success with intraoperative cholangiography and choledochoscopy has inspired some authors to address the issue of removing calculi from the bile ducts during the same laparoscopic operation ('single stage procedure'). Stones can be extracted by using a Dormia basket under fluoroscopic or direct choledochoscopic control. Laparoscopic CBD clearance can be obtained in up to $77 \%$ of cases; only proximal stones, in the hepatic ducts or in the intrahepatic biliary tract, are not in the reach of intraoperative choledochoscopy. The single-stage approach requires a shorter hospital stay; therefore, the superiority of ES to surgical CBD exploration has been disputed by maximum invasive surgery. Moreover, transcystic stone extraction is better than choledochotomy in terms of morbidity and length of hospitalization. Quite often, it is necessary to position a T-tube or a transcystic drain after surgical CBD exploration; these drains are left in place for a few weeks, resulting in far greater distress for the patient than expected. Nonetheless, because no better method has yet been found, 'single stage' treatment of associated calculi can be obtained by performing ES during $\operatorname{LC}(8,12,18)$.

If ductal stones, identified during LC, cannot be removed 
surgically because of technical or anatomical problems, or a lack of expertise, intraoperative ES can spare the patient an uncomfortable postoperative procedure. Questions regarding the ease and safety of cannulating and cutting the papilla in a supine patient were solved when it became evident that there are no additional difficulties and that the technique may even be easier than the traditional prone-left lateral position. The patient is put under general endotracheal anesthesia, and, in cases of difficult cannulation of the papilla, a guidewire, pushed by the surgeon into the cystic duct down to the duodenum, can be retrieved by the endoscopist (socalled laparoscopic-endoscopic rendez vous). If possible, the proximal jejunum should be clamped to reduce intestinal overinflation and postoperative discomfort. Our experience has evolved through all the different steps of management of associated stones. Patients' preference for a single-stage approach has induced us to challenge ourselves with laparoscopic bile duct stone extraction $(10,19,20)$. Specialized equipment has improved our results, but failures are still frequent and complications may follow, especially after choledochotomy. Avoidance of T-tube drainage is in accordance with the principles of minimally invasive surgery, but from our point of view, it does not seem reasonable. Because

\section{REFERENCES}

1. Montori A. New era of operative gastroenterology: rigid and flexible endoscopes working together. First Integrated ESGE Postgraduate Course for Eastern European Countries. Miskolc, July 5-8, 1995.

2. Barrat C, Turner R, Rizk N, Vinurel M, Champault G. Is there an age limit for laparoscopic cholecystectomy? Apropos of 61 patients over 85 years of age. J Chir (Paris) 1996;133:9-10, 414-7.

3. Firilas A, Duke BE, Max MH. Laparoscopic cholecystectomy in the elderly. Surg Endosc 1996;101:33-5.

4. Berci G. Back to basics. Int J Surg Sci 1998;5:5.

5. Montori A, Miscusi G, Masoni L, Gasparrini M, Onorato M. Peroperative endoscopic sphyncterotomy during laparoscopic cholecystectomy, 6th United European Gastroenterology Week, Birmingham, October 18-23, 1997.

6. Montori A. Nuove realtà operative in endoscopia digestiva. XII Congr Naz Soc It Medico-Chirurg Patol Apparato Digerente, Cologna, June 4-6, 1991.

7. Montori A. Progresso tecnologico e chirurgia generale. V Congresso Nazionale Capitolo It, American College of Surgeons, Ascoli Piceo, April 28 to March 1, 1991.

8. Miscusi G, Gasparrini M, Masoni L, De Anna L, Taglienti D, Montori A. Complicanze Della Colecistectomia Laparoscopica. La Chirurgia Mini-Invasiva Toraco-Laparoscopica, Bari, July 8-9 1994.

9. Montori A. La chirurgia mininvasiva verso il 2000: attualità e prospettive. Meeting Internazionale 'Attualità in Chirurgia VideoToraco-Laparoscopica', Messina-Milazzo, June 1995.

10. Montori A. Minimally invasive surgery endoscopy. Endoscopy 1998;30:244-52.

11. Hashimoto D. Gasless laparoscopy by subcutaneous system. Sixth World Congress of Endoscopic Surgery. Rome, June 3-6, 1998:253-6.

12. Cuschieri A, Croce E, Faggioni A, et al. EAES ductal stone study. of the unexpected ease and high success rate of single-stage LC plus ES, we prefer to use this method unless a transcystic route seems straightforward (few, small stones and dilated cystic duct). Moreover, no significant morbidity has been observed in our first cases; thus, our experience is in line with previous evidence of better control of the bile ducts from the lowest possible site, ie, the Vater's papilla (12). Contraindications are the same as for any endoscopic approach to the Vater's ampoule. Failure of ES does not prevent us from attempting laparoscopic choledochotomy.

\section{CONCLUSIONS}

We can affirm that elderly patients with uncomplicated gallstone disease are excellent candidates for LC.

This procedure may also be performed safely in elderly patients classified as American Society of Anesthesiologists' class III, with increased cardiac risk; accurate preoperative evaluation, intra- and postoperative monitoring of vital parameters helps reduce morbidity and mortality $(10,21)$.

In subjects with acute complications of cholelithiasis, gasless LC (LaparoTenser or Laparolift) is preferred because an excessive duration of operation is the single most important reason for converting to an open cholecystectomy.
Preliminary findings of multi-center prospective randomized trial comparing two-stage vs single-stage management. Surg Endosc 1996;10:1130-5

13. Gersin KS, Fanelli RD. Laparoscopic endobiliary stenting as an adjunct to common bile duct exploration. Surg Endosc 1998;12:301-4.

14. Cuschier A, Terblanche J. Laparoscopic cholecystectomy: evolution not revolution. Surg Endoscopy 1990;4:125-6.

15. Montori A, Masoni L, de Anna L. Intraoperative Videocholangioscopy. Imaging and Computing in Gastroenterology. Berlin: Springer-Verlag, 1991.

16. Miscusi G, Pietropaolo V, Bogliolo G, et al. Il Trattamento Endoscopico Della Litiasi Della Via Biliare Principale. Atti Dei XIII Incontri Di Chirurgia A, Foggia, March 25-27, 1993.

17. Perissat J, Collet D, Beliard R, Desplantez J. Indications Du Traitment De La Lithiase Du Choledoque À L'Heure De La Chirurgie Coelioscopique. XVII Es Journees Nicoisess Pathologie Et Chirurgie Digestives Video-Laparoscopie. Nice, February 10-11, 1995.

18. Mayrhofer T. Intraoperative Anterograde Sphincterotomy XVII Es Journees Nicoisess Pathologie Et Chirurgie Digestives VideoLaparoscopie. Nice, February 10-11, 1995

19. Schol FPG, Go P, Gouma DJ. Outcome Of 49 repairs of bile duct injuries after laparoscopic cholecystectomy. World J Surg 1995;19:753-7.

20. Montori A. La chirurgia mininvasiva: un mito o una realtà del domani? VI Congr Naz Ital Chaptr, American College of Surgeons. Cortina, February 12-14, 1992.

21. Cuschieri A. Adverse cardiovascular changes induced by positive pressure pneumoperitoneum. Possible solution to a problem. Surg Endosc 1998;12:93-4. 


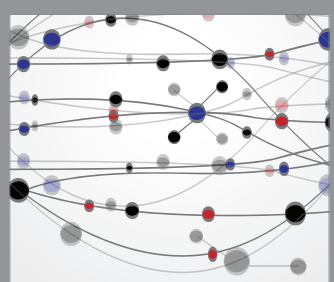

The Scientific World Journal
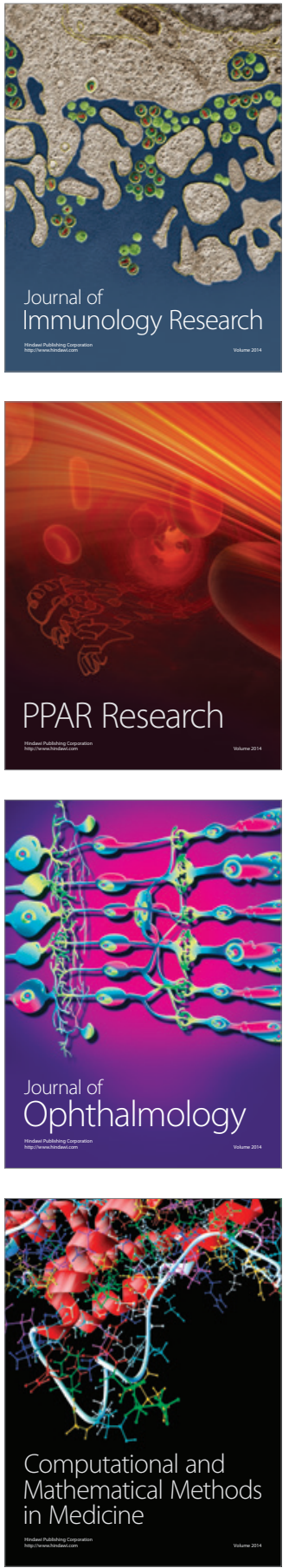

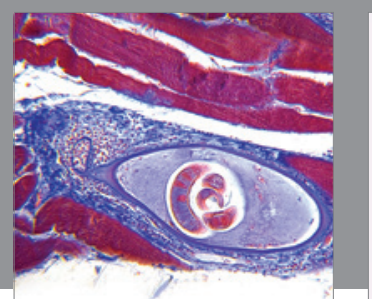

Gastroenterology Research and Practice

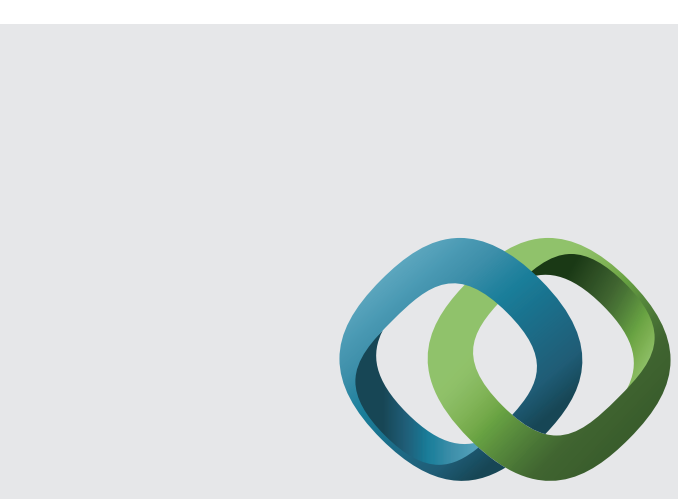

\section{Hindawi}

Submit your manuscripts at

http://www.hindawi.com
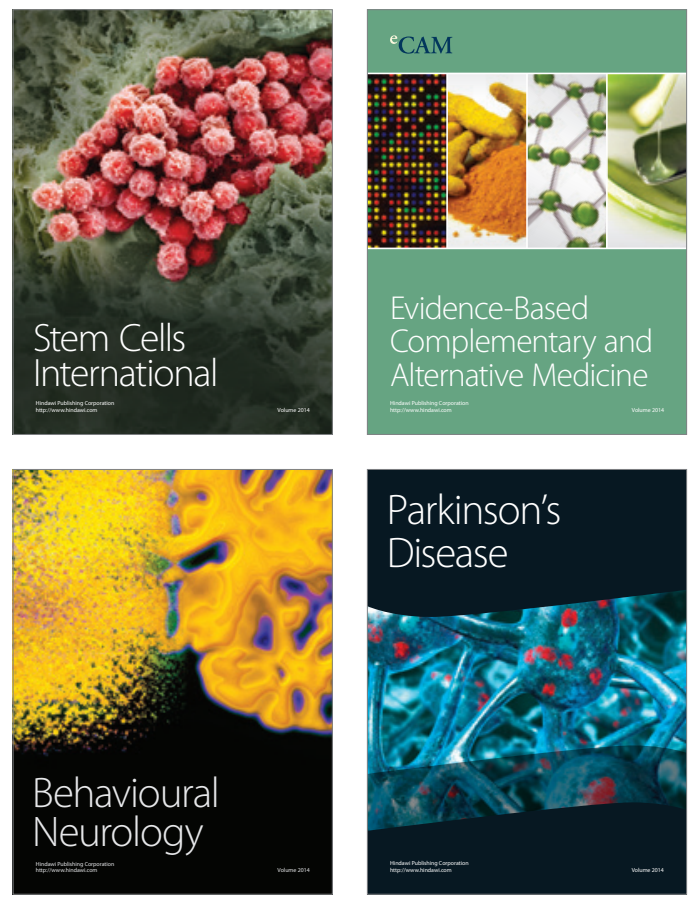
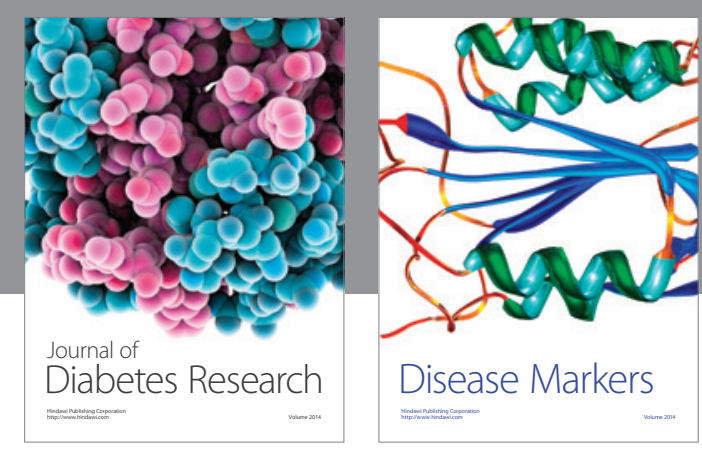

Disease Markers
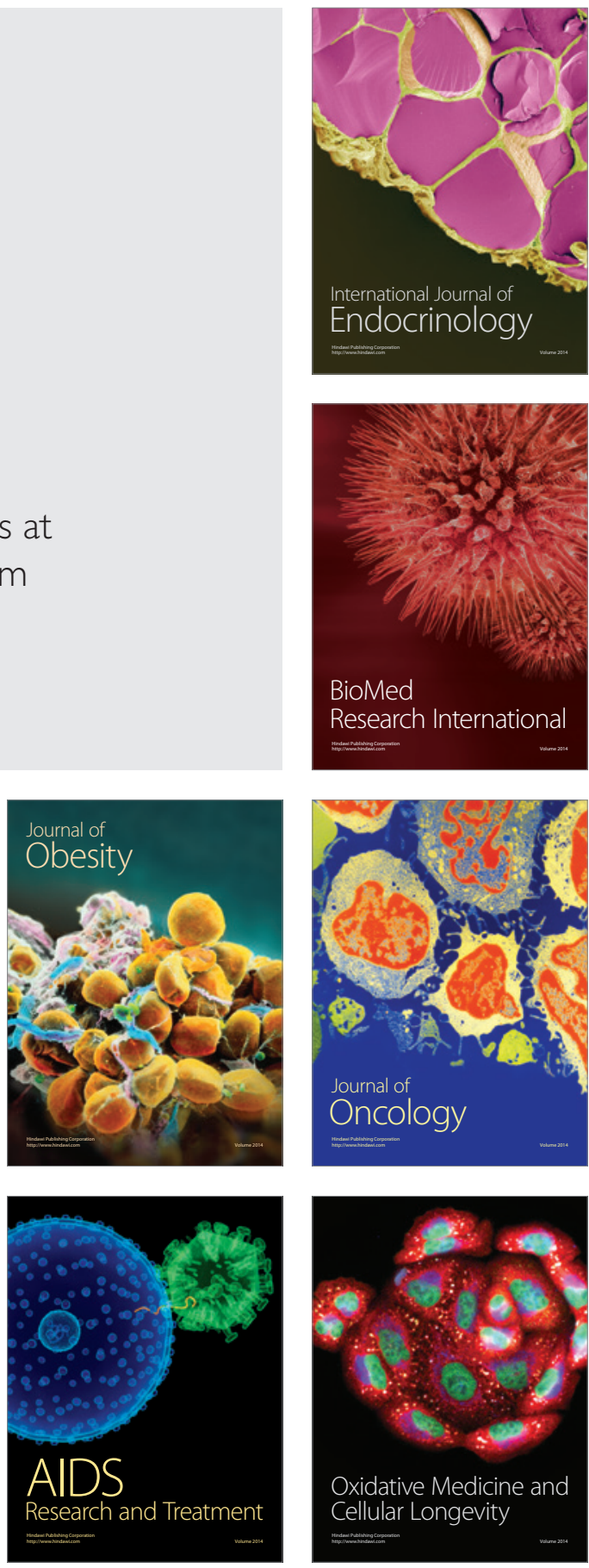